\title{
miR-19a and miR-20a and Tissue Factor Expression in Activated Human Peripheral Blood Mononuclear Cells
}

\author{
Cristina Balia, Mirella Giordano, Valentina Scalise, Tommaso Neri, Gabriella Fontanini, \\ Fulvio Basolo, Alessandro Celi, and Roberto Pedrinelli
}

Dipartimento di Patologia Chirurgica, Medica, Molecolare e dell'Area Critica, Università di Pisa, Pisa, Italy

Correspondence should be addressed to Roberto Pedrinelli; roberto.pedrinelli@med.unipi.it

Received 9 July 2017; Revised 10 September 2017; Accepted 24 September 2017; Published 30 October 2017

Academic Editor: Giovanni de Gaetano

Copyright (C) 2017 Cristina Balia et al. This is an open access article distributed under the Creative Commons Attribution License, which permits unrestricted use, distribution, and reproduction in any medium, provided the original work is properly cited.

\begin{abstract}
Background and Aims. To investigate the behaviour of miR-19a and miR-20a, two microRNAs involved in posttranscriptional modulation of TF expression in peripheral blood mononuclear cells (PBMCs) exposed to high glucose (HG) and lipopolysaccharide (LPS), and to evaluate the involvement of angiotensin II in that process. Methods. TF Procoagulant Activity (PCA, one-stage clotting assay), antigen (Ag, ELISA), and miR-19a and miR-20a levels (specific TaqMan ${ }^{\circledR}$ MicroRNA Assays) were evaluated in PBMCs exposed to high glucose (HG, $50 \mathrm{mM})$, LPS $(100 \mathrm{ng} / \mathrm{mL})$, and Olmesartan $\left(\mathrm{OLM}, 10^{-6} \mathrm{M}\right)$, an angiotensin II type 1 receptor antagonist. Results. HG increased TF expression and decreased both miRs as compared to control glucose conditions (11.1 mM). In HG-activated PBMCs, LPS stimulated TF expression and downregulated miR-20a, an effect reverted by OLM (10 $\left.{ }^{-6} \mathrm{M}\right) ; \mathrm{miR}-19 \mathrm{a}$ expression was unchanged by LPS in both CG and HG conditions. Conclusions. miR-19a and miR-20a are inhibited by inflammatory stimuli active on TF expression and their response differs by the stimulus under investigation; angiotensin II may participate in that mechanism.
\end{abstract}

\section{Introduction}

MicroRNAs (miRs) are small, 22 -nucleotide noncoding RNAs that inhibit transcriptional gene expression by interacting with sites of complementarity in the $3^{\prime}$ untranslated regions (3-UTR) of target mRNAs [e.g., [1]]. Posttranscriptional gene modulation by miRs involves several genes including Tissue Factor (TF) [2], the principal initiator of the clotting cascade, and a major regulator of haemostasis and thrombosis [3] expressed by circulating monocytes exposed to proinflammatory stimuli such as lipopolysaccharide (LPS, endotoxin) [3] and high glucose (HG) [4]. Locally generated angiotensin (AT)II, the effector arm of the renin angiotensin system (RAS), contributes actively to that inflammatory process [5], a mechanism downregulated by ATII type 1 receptor (AT1R) blockade $[4,5]$.

Among other potentially significant miRs interacting with TF gene [2], miR-19a and miR-20a have recently been shown to modulate TF expression in monocytes of patients with immune-mediated diseases [6]. That information, obtained in a very specific context, raises the issue of the behaviour of those two noncoding RNAs in response to stimuli active on TF expression in peripheral blood mononuclear cells (PBMCs) harvested from normal subjects activated by HG and LPS and whether ATII is involved in that relationship, an issue that has never been addressed insofar.

\section{Materials and Methods}

2.1. Cell Isolation and Culture. Human PBMC suspensions were obtained from unpooled buffy coats left over from blood bank draws taken from healthy donors, kept at room temperature, and utilized within a maximum of 4 hours from withdrawal. As detailed elsewhere [4], leukocytes were isolated from fresh buffy coats diluted $1: 1$ with sodium citrate $0.38 \%$ in saline solution, mixed gently with 0.5 volume of $2 \%$ Dextran T500, and left for 40 min for erythrocyte sedimentation. The leukocyte-rich supernatant was recovered and centrifuged for $10 \mathrm{~min}$ at $200 \times \mathrm{g}$. The pellet was resuspended in $30 \mathrm{~mL}$ of sodium citrate solution, layered over $15 \mathrm{~mL}$ of Ficoll-Histopaque, and centrifuged for $30 \mathrm{~min}$ at $400 \times \mathrm{g}$ at $20^{\circ} \mathrm{C}$. The PBMC-rich ring was recovered, washed twice in 
sodium citrate $0.38 \%$, and resuspended in polypropylene tubes in RPMI 1640 medium supplemented with $100 \mathrm{U} / \mathrm{mL}$ penicillin-streptomycin.

Glucose perturbation was induced by supplementing PBMC cultures with D-glucose to reach a final concentration of $50 \mathrm{mM}$ (from now on referred to as high glucose (HG)) to be compared with cells cultured in unsupplemented RPMI 1640 medium containing $11.1 \mathrm{mM} \mathrm{D}$-glucose (from now on referred to as control glucose (CG)). Previous studies had excluded interferences derived from hypertonicity [4].

Drugs were kept in stock solution and diluted in serumfree RPMI at the appropriate concentrations immediately before use. Cell viability, as assessed by dimethyl thiazolyl diphenyl tetrazolium (MTT), was verified ( $>85 \%$ of viable cells) throughout all experimental phases.

The final PBMC preparations typically contain 25-35\% monocytes, negligible proportions of neutrophils $(<5 \%)$, and 65-75\% lymphocytes.

All reagents and solutions used for cell isolation and culture were prepared with endotoxin-free water and glassware was rendered endotoxin-free by exposure to high temperature. Drugs were kept in stock solution and diluted in serumfree RPMI at the appropriate concentrations immediately before use.

Confounding from interindividual differences in TF sensitivity to proinflammatory stimuli was avoided by using unpooled buffy coats of the same subject throughout the different phases of the experimental series.

2.2. TF Procoagulant Activity (PCA). PCA was assessed by one-stage clotting time in PBMCs disrupted by three freezethaw cycles as described in [4]. Time to clot formation was recorded and values converted to arbitrary units (AU) by comparison with a standard human brain TF calibration curve covering clotting times from 20 to $600 \mathrm{~s}$. The standard TF preparation was arbitrarily assigned a value of $1000 \mathrm{AU} / \mathrm{mL}$ and a representative conversion of clotting times to AU is as follows: $100 \mathrm{AU}-21 \mathrm{~s}, 10 \mathrm{AU}-40 \mathrm{~s}, 1 \mathrm{AU}-82 \mathrm{~s}$, 0.1-187 s, 0.01 AU-375 s, and 0.001 AU- 600 s. Experiments were run in triplicate and averaged.

2.3. TF Antigen (Ag). Cells were disrupted by three repeated freeze-thaw cycles and TF extracted with a buffer of Tris buffered saline (50 mM Tris, $100 \mathrm{mM} \mathrm{NaCl}$, pH 7.4) containing $0.1 \%$ Triton $\mathrm{X}-100$. After an overnight extraction, the debris was pelleted by centrifugation at $100 \times \mathrm{g}$ for $1 \mathrm{~h}$ at $4^{\circ} \mathrm{C}$ and supernatants were used for ELISA (Imubind TF kit Sekisui Diagnostics, West Malling, United Kingdom). $\mathrm{TF}$ Ag levels were expressed in $\mathrm{pg} / \mathrm{mL}$ using a reference curve created by the TF standards. Within and between assay variability were 3.5 and $5.5 \%$, respectively.

2.4. miRs Expression. Total RNA including miRs was isolated from PBMCs using the miRNeasy Mini Kit (Qiagen), according to the manufacturer's instructions. RNA samples, after quality and quantity evaluation using a NanoDrop ND1000 spectrophotometer, were stored at $-80^{\circ} \mathrm{C}$ until used in the experiments. Quantification of miR-19a, miR-20a, and RNU6B (as housekeeping gene) expression was carried out in triplicate using specific TaqMan MicroRNA Assays (Applied Biosystems), according to the manufacturer's instructions. Briefly, 10 ng of RNA was retrotranscribed by the Taq-Man ${ }^{\circledR}$ MicroRNA Reverse Transcription (RT) Kit (Applied Biosystems) using individual miR-specific RT primers, and $1.3 \mu \mathrm{l}$ of RT product was analyzed by quantitative Real Time-PCR (qRT-PCR) on the Rotor-Gene 6000 (Corbett Research). Threshold cycle $(\mathrm{Ct})$ and baselines were determined by manual settings. miR expression was calculated by relative quantification and fold expression changes were determined by the $2^{-\Delta \Delta C t}$ method using the DataAssistTM software (Applied Biosystems). miR changes were analyzed as percent changes from either CG or HG used as referents.

TF PCA and Ag and miR levels were assayed after a $18 \mathrm{hr}$ and $2 \mathrm{hr}$ incubation interval, respectively. PCA, ELISA, and qRT-PCR results in both control and experimental groups were obtained from suspensions containing equal number of cells $\left(3 \times 10^{6} \mathrm{PBMCs} / \mathrm{mL}\right)$.

2.5. Experimental Design. The study included two series of experiments. The first series $(n=4)$ evaluated the effect on miR-19a and miR-20a and TF expression of HG versus CG and the second one $(n=9)$ evaluated the effect of LPS (100 ng/mL) stimulation on PBMCs incubated in CG or HG conditions, either per se or in presence of Olmesartan (OLM) $\left(10^{-6} \mathrm{M}\right)$, an ATII type 1 receptor (AT1R) antagonist [7].

2.6. Statistics. Statistical differences were tested by Wilcoxon test for paired comparisons on absolute data (TF PCA and $\mathrm{Ag}$ ) or percent changes (miR expression) from control conditions normalized to $100 \%$. Data were reported as means $\pm \mathrm{SD}$ and a two-tailed $p$-level $<0.05$ was the threshold for statistical significance.

\section{Results}

As compared with CG, HG inhibited miR-19a and miR-20a expression and induced a highly significant stimulation of both TF PCA and TF Ag (Figures 1(a) and 1(b)).

LPS increased TF PCA and TF Ag in both CG and HG conditions (Figures 2(a) and 3(a)). In CG conditions, miR20a levels in response to LPS showed inconsistent changes but decreased in presence of $\mathrm{HG}$, a trend reverted by AT1R blockade through OLM (Figures 2(b) and 3(b)).

miR-19a levels were insensitive to LPS stimulation in either of experimental conditions (Figures 2(b) and 3(b)).

\section{Discussion}

This study shows inhibition of both miR-19a and miR20a in response to $\mathrm{HG}$ [4], a procoagulant [4, present results] and proinflammatory stimulus [8-10] that activates $\mathrm{NF}-\kappa \mathrm{B}[10,11]$, a redox-sensitive transcription factor [12] critical for TF gene expression [3]. Notably, cytoplasmic miRinduced silencing complexes restrain TF protein translation and destabilize TF mRNA by binding to the $3^{\prime}$-UTR of TF transcripts [1] and binding sites for both miR-19a and miR-20a have been recognized in the $3^{\prime}$-UTR of the TF mRNA transcript in human monocytes [6] and other 


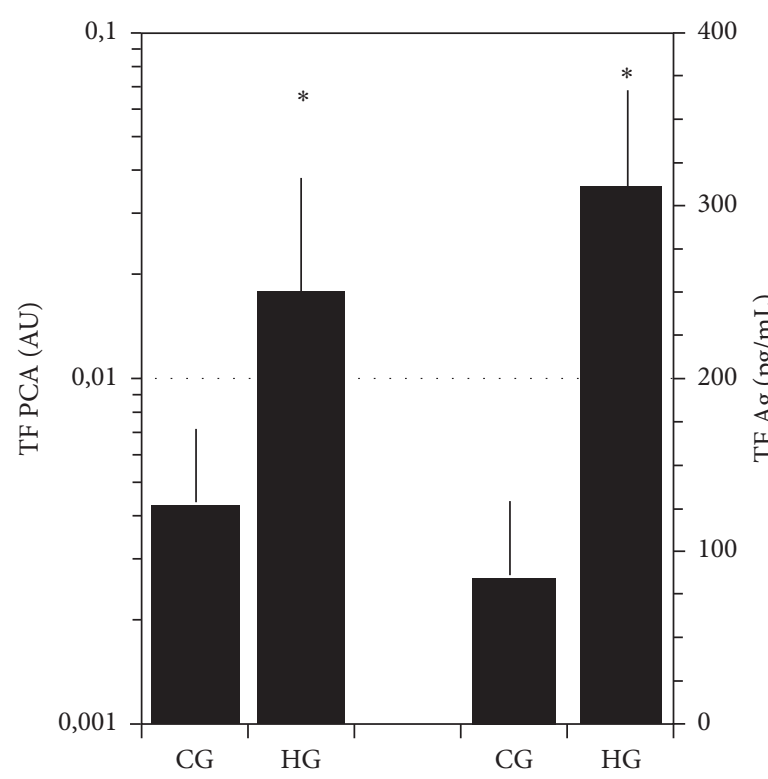

(a)

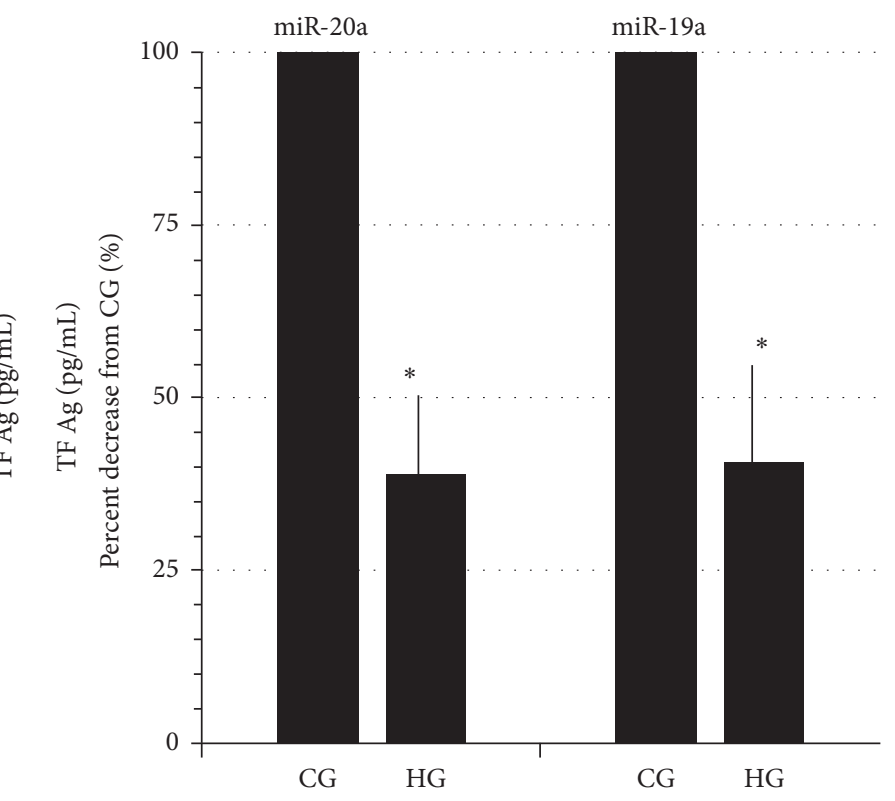

(b)

Figure 1: (a) High glucose (HG, $50 \mathrm{mM}$ )-induced stimulation of TF PCA (left ordinate, log scale) and TF Ag (right ordinate). (b) Downregulation of miR-20a and miR-19a expression in response to HG as compared with control glucose (CG, $11.1 \mathrm{mM})$. Means \pm SD; $N=4,{ }^{*} p<0.001 \mathrm{HG}$ versus CG.

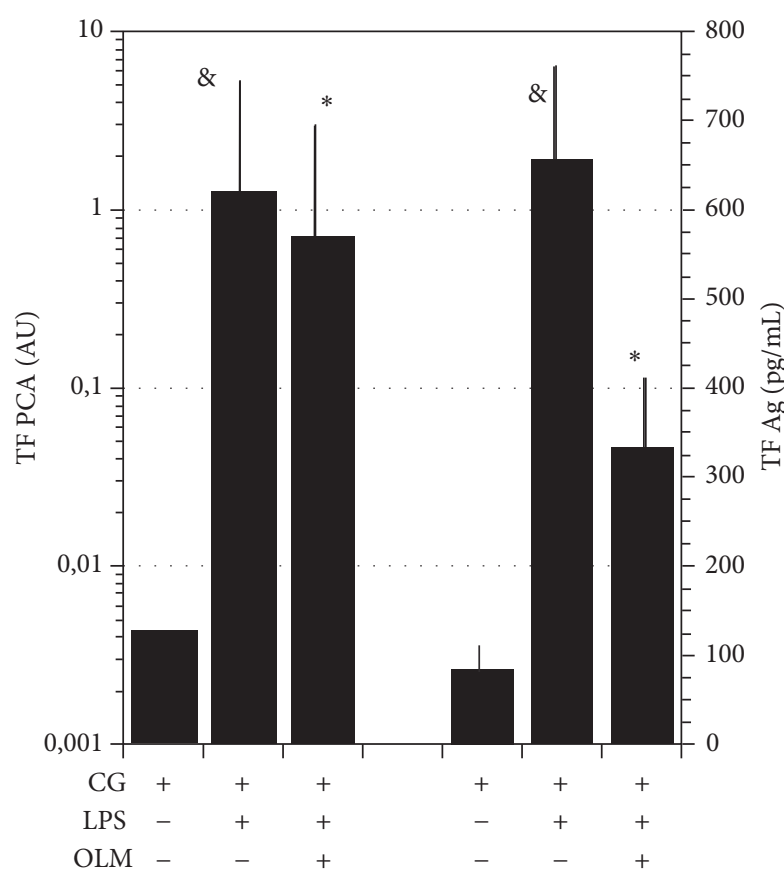

(a)

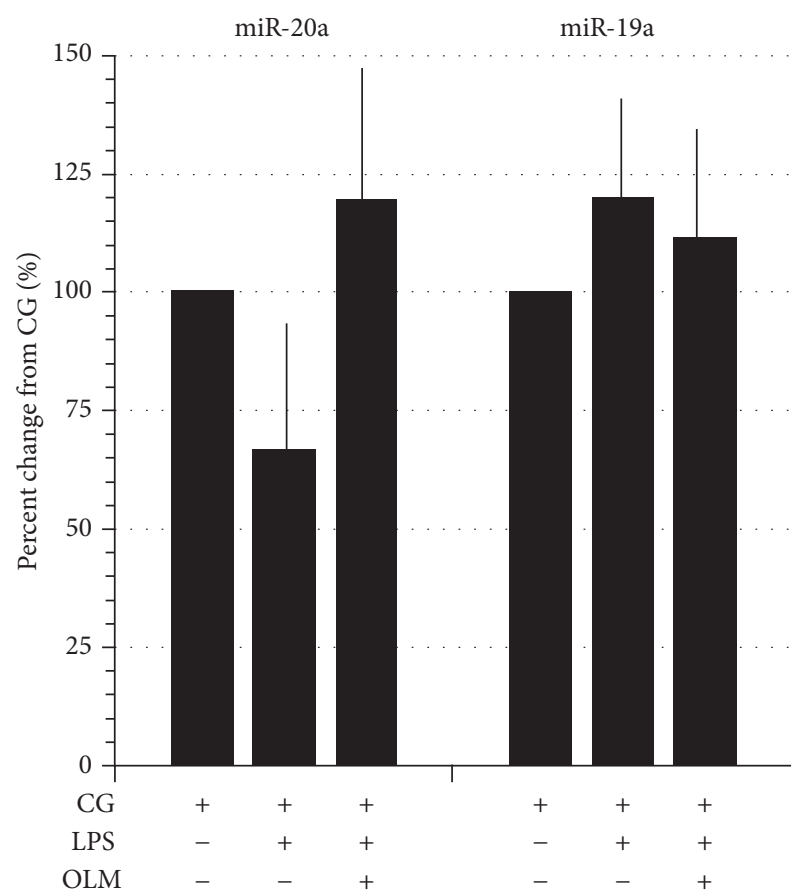

(b)

FIGURE 2: (a) LPS (100 ng/mL)-induced stimulation of TF PCA (left ordinate, log scale) and Ag (right ordinate) downregulated by AT1R blockade through Olmesartan (OLM, $\left.10^{-6} \mathrm{M}\right)$. PBMCs incubated in control glucose (CG, 11.1 mM). (b) Percent changes of miR-20a and miR19a in LPS-stimulated PBMCs per se or in presence of OLM $\left(10^{-6} \mathrm{M}\right)$. Data expressed as percent changes from CG. Means \pm SD, $N=9$. ${ }^{\&} p<0.001$ LPS versus CG; ${ }^{*} p<0.001$ OLM + LPS versus LPS. 


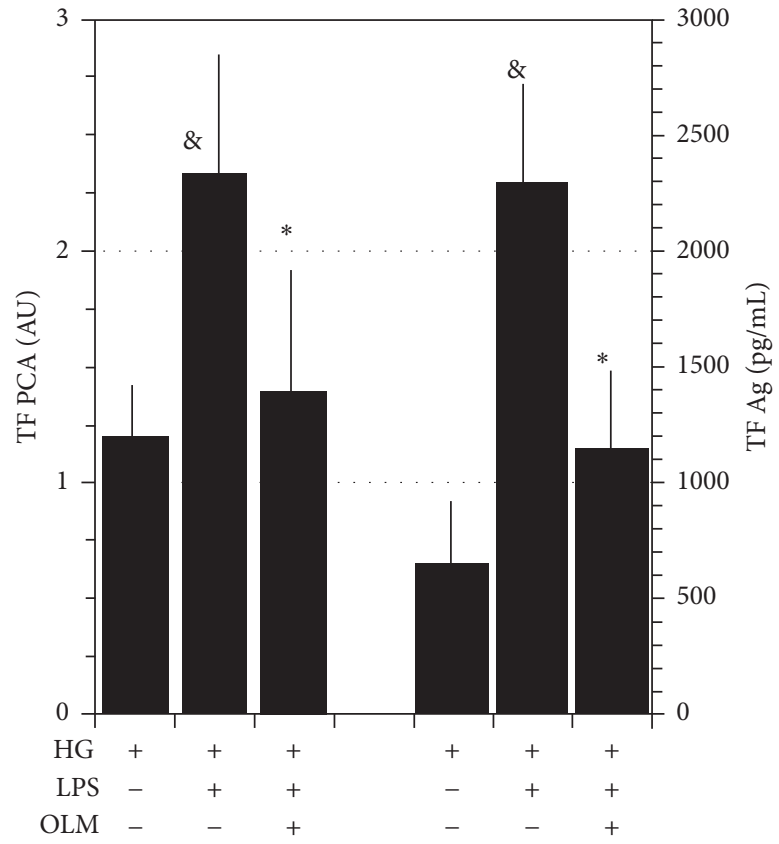

(a)

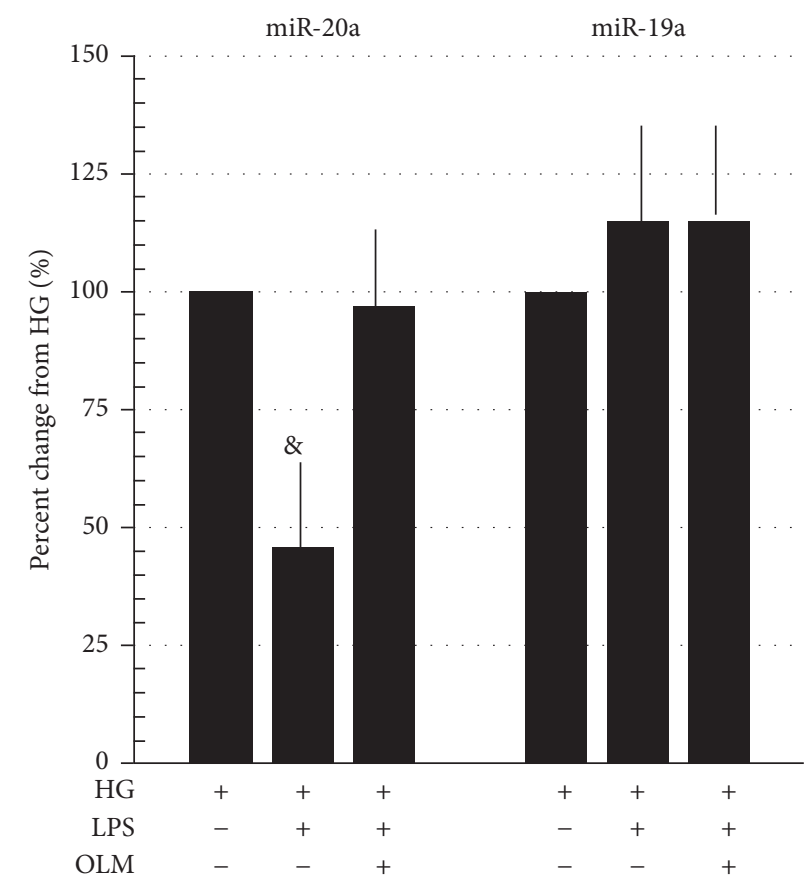

(b)

FIGURE 3: (a) LPS (100 ng/mL)-induced stimulation of TF PCA (left ordinate) (note the scale difference with the same parameter reported in Figure 2) and Ag (right ordinate) downregulation by AT1R blockade through Olmesartan (OLM, $\left.10^{-6} \mathrm{M}\right)$; PBMCs incubated in high glucose (HG, $50 \mathrm{mM})$. (b) Percent changes of miR-20a and miR-19a in LPS-stimulated PBMCs per se or in presence of OLM $\left(10^{-6} \mathrm{M}\right)$. Data expressed as percent changes from HG. Means $\pm \mathrm{SD}, N=9 .{ }^{\&} p<0.001 \mathrm{LPS}$ versus $\mathrm{HG} ;{ }^{*} p<0.001 \mathrm{LPS}+\mathrm{OLM}$ versus LPS.

cell types as well $[13,14]$. Therefore, downregulated miRs expression by HG may conceivably facilitate HG-induced TF expression, a mechanism possibly contributing to the hypercoagulable state induced by high blood glucose in diabetic patients [15]. However, our PBMCs were perturbed by glucose concentrations far beyond that reached clinically and, therefore, the present results are to be seen as preliminary observations awaiting further validation in more physiological conditions. Moreover, we carried out these experiments in cell lysates, a preparation differing in several ways from intact cells such as, for example, amplification of procoagulant responses due to exposure of anionic phospholipids from disrupted membranes [16]. Therefore, the present results may not necessarily be extrapolated to intact PBMC, a point that deserves attention in future studies.

A second result of this study worth of comment relates to the inhibition by LPS of miR-20a in HG-activated PBMCs, an effect compatible with attenuation of a negative posttranscriptional feedback loop on TF expression in interaction with HG-induced excess ROS production and NFkB overactivation [8-11]. On the other hand, LPS stimulation did not change miR-19a levels in our PBMC preparations at variance, in this respect, with human umbilical vein endothelial cells (HUVECs), a cell line capable of rapid TF induction [17] in which endotoxin downregulated miR-19a expression [18]. Thus, the control mechanism of miR-19a may vary according to the tissue under evaluation, a speculative possibility in need of experimental verification.
A third and intriguing point emerging from these results was the reversal of LPS-induced miR-20a downregulation by OLM, an ATIR blocker that, as expected $[4,5]$, inhibited both TF PCA and TF Ag. That effect, reminiscent, to some extent, of results reported by other authors [19], suggests an involvement of ATII in posttranscriptional regulation of LPS-induced procoagulant activity. This speculative possibility adds a new hypothetical component to the intricate interrelationship between locally generated ATII and LPS [20-22], a major marker for the recognition of intruding Gram-negative bacteria by the innate immune system that initiates the pathogen-induced inflammatory response [23] of which activation of coagulation is a prominent component [24]. However, any role of ATII in the posttranscriptional control of inflammationinduced TF expression is only hypothetical at the moment and needs further studies including confirmation of the present findings by using other RAS antagonists such as ACE inhibitors and ATII receptor antagonists different from OLM.

\section{Conclusions}

The results of this study disclose behaviours of miR-19a and miR-20a potentially involved in the posttranscriptional regulation of TF expression in the context of the complex interplay among inflammation, coagulation, and ATII, in which TF plays a pivotal role. 


\section{Abbreviations}

$\begin{array}{ll}\text { Ag: } & \text { Antigen } \\ \text { ATII: } & \text { Angiotensin II } \\ \text { AT1R: } & \text { Angiotensin II type 1 receptor } \\ \text { AU: } & \text { Arbitrary units } \\ \text { CG: } & \text { Control glucose } \\ \text { ELISA: } & \text { Enzyme-linked immunosorbent assay } \\ \text { HG: } & \text { High glucose } \\ \text { miR: } & \text { MicroRNA } \\ \text { MTT: } & \text { Dimethyl thiazolyl diphenyl tetrazolium } \\ \text { OLM: } & \text { Olmesartan } \\ \text { PBMC: } & \text { Peripheral blood mononuclear cell } \\ \text { PCA: } & \text { Procoagulant activity } \\ \text { qRT-PCR: } & \text { Quantitative real time polymerase chain } \\ & \text { reaction } \\ \text { RAS: } & \text { Renin angiotensin system } \\ \text { RNA: } & \text { Deoxyribonucleic acid } \\ \text { ROS: } & \text { Reactive oxygen species } \\ \text { RPMI: } & \text { Roswell Park Memorial Institute } \\ \text { SD: } & \text { Standard deviation } \\ \text { TF: } & \text { Tissue factor. }\end{array}$

\section{Data Access}

The datasets analyzed during the current study are available from the corresponding author on reasonable request.

\section{Ethical Approval}

Collection of buffy coats from donors and their subsequent processing were approved by the ethics committee of the Azienda Ospedaliero, Universitaria Pisana.

\section{Conflicts of Interest}

The authors declare that they have no conflicts of interest.

\section{Authors' Contributions}

Cristina Balia carried out the PCA studies; Mirella Giordano carried out the miR expression; Valentina Scalise carried out TF antigen experiments; Tommaso Neri performed the statistical analysis; Gabriella Fontanini, Fulvio Basolo, and Alessandro Celi participated in design of the study; Roberto Pedrinelli conceived the study and coordinated the research team. All authors read and approved the final manuscript. Cristina Balia and Mirella Giordano contributed equally to the study.

\section{Acknowledgments}

Funding for the study was provided by grants from Università degli Studi di Pisa. All authors are part of the teaching and research staff of the Università degli Studi di Pisa.

\section{References}

[1] A. Eulalio, E. Huntzinger, and E. Izaurralde, "Getting to the root of miRNA-mediated gene silencing," Cell, vol. 132, no. 1, pp. 9$14,2008$.
[2] A. Eisenreich and U. Leppert, "The impact of microRNAs on the regulation of tissue factor biology," Trends in Cardiovascular Medicine, vol. 24, no. 3, pp. 128-132, 2014.

[3] E. Camerer, A.-B. Kolstø, and H. Prydz, "Cell biology of tissue factor, the principal initiator of blood coagulation," Thrombosis Research, vol. 81, no. 1, pp. 1-41, 1996.

[4] C. Balia, S. Petrini, C. Cordazzo et al., "High glucose potentiates and renin-angiotensin blockade downregulates LPS-induced tissue factor expression in human mononuclear cells," Thrombosis Research, vol. 130, no. 3, pp. 552-556, 2012.

[5] E. Napoleone, A. Di Santo, M. Camera, E. Tremoli, and R. Lorenzet, "Angiotensin-converting enzyme inhibitors downregulate tissue factor synthesis in monocytes," Circulation Research, vol. 86, no. 2, pp. 139-143, 2000.

[6] R. Teruel, C. Pérez-Sánchez, J. Corral et al., "Identification of miRNAs as potential modulators of tissue factor expression in patients with systemic lupus erythematosus and antiphospholipid syndrome," Journal of Thrombosis and Haemostasis, vol. 9, no. 10, pp. 1985-1992, 2011.

[7] S. H. Lee, Y. S. Jung, B. H. Lee, S. I. Yun, S. E. Yoo, and H. S. Shin, "Characterization of angiotensin II antagonism displayed by SK-1080, a novel nonpeptide AT1-receptor antagonist," Journal of Cardiovascular Pharmacology, vol. 33, no. 3, pp. 367-374, 1999.

[8] T. Nishikawa, D. Edelstein, X. L. Du et al., "Normalizing mitochondrial superoxide production blocks three pathways of hyperglycaemic damage," Nature, vol. 404, no. 6779, pp. 787790, 2000.

[9] N. Shanmugam, M. A. Reddy, M. Guha, and R. Natarajan, "High glucose-induced expression of proinflammatory cytokine and chemokine genes in monocytic cells," Diabetes, vol. 52, no. 5, pp. 1256-1264, 2003.

[10] Y. Iwasaki, M. Kambayashi, M. Asai, M. Yoshida, T. Nigawara, and K. Hashimoto, "High glucose alone, as well as in combination with proinflammatory cytokines, stimulates nuclear factor kappa-B-mediated transcription in hepatocytes in vitro," Journal of Diabetes and its Complications, vol. 21, no. 1, pp. 5662, 2007.

[11] C. Balia, V. Scalise, S. Cianchetti et al., "The effect of high glucose on the inhibitory action of C21, a selective AT2R agonist, of LPS-stimulated tissue factor expression in human mononuclear cells," Journal of Inflammation (United Kingdom), vol. 13, no. 1, article no. 123, 2016.

[12] R. Schreck, K. Albermann, and P. A. Baeuerle, "Nuclear factor $\kappa \beta$ : an oxidative stress-responsive transcription factor of eukaryotic cells (a review)," Free Radical Research Communications, vol. 17, no. 4, pp. 221-237, 1992.

[13] X. Zhang, H. Yu, J. R. Lou et al., "MicroRNA-19 (miR-19) regulates tissue factor expression in breast cancer cells," The Journal of Biological Chemistry, vol. 286, no. 2, pp. 1429-1435, 2011.

[14] G. Yu, H. Li, X. Wang et al., "MicroRNA-19a targets tissue factor to inhibit colon cancer cells migration and invasion," Molecular and Cellular Biochemistry, vol. 380, no. 1-2, pp. 239-247, 2013.

[15] V. R. Vaidyula, A. K. Rao, M. Mozzoli, C. Homko, P. Cheung, and G. Boden, "Effects of hyperglycemia and hyperinsulinemia on circulating tissue factor procoagulant activity and platelet CD40 ligand," Diabetes, vol. 55, no. 1, pp. 202-208, 2006.

[16] T. A. Drake, W. Ruf, J. H. Morrissey, and T. S. Edgington, "Functional tissue factor is entirely cell surface expressed on lipopolysaccharide-stimulated human blood monocytes and a 
constitutively tissue factor-producing neoplastic cell line," The Journal of Cell Biology, vol. 109, no. 1, pp. 389-395, 1989.

[17] M. Colucci, G. Balconi, R. Lorenzet et al., "Cultured human endothelial cells generate tissue factor in response to endotoxin," The Journal of Clinical Investigation, vol. 71, no. 6, pp. 1893-1896, 1983.

[18] W.-L. Jiang, Y.-F. Zhang, Q.-Q. Xia et al., "MicroRNA-19a regulates lipopolysaccharide-induced endothelial cell apoptosis through modulation of apoptosis signal-regulating kinase 1 expression," BMC Molecular Biology, vol. 16, article no. 11, 2015.

[19] S. Gao, T.-W. Liu, Z. Wang et al., "Downregulation of MicroRNA-19b contributes to angiotensin II-induced overexpression of connective tissue growth factor in cardiomyocytes," Cardiology, vol. 127, no. 2, pp. 114-120, 2014.

[20] J. Wu, X. Yang, Y.-F. Zhang et al., "Angiotensin II upregulates Toll-like receptor 4 and enhances lipopolysaccharide-induced CD40 expression in rat peritoneal mesothelial cells," Inflammation Research, vol. 58, no. 8, pp. 473-482, 2009.

[21] Y. Ji, J. Liu, Z. Wang, and N. Liu, "Angiotensin II induces inflammatory response partly via toll-like receptor 4-dependent signaling pathway in vascular smooth muscle cells," Cellular Physiology and Biochemistry, vol. 23, no. 4-6, pp. 265-276, 2009.

[22] J. Luo, J. Sun, and D. Cai, "Effect of activating Toll-like receptor 4 on renin-angiotensin system in 3T3-L1 adipose cells," Journal of Central South University of Technology, vol. 34, pp. 787-791, 2014.

[23] B. Beutler, K. Hoebe, X. Du, and R. J. Ulevitch, "How we detect microbes and respond to them: the Toll-like receptors and their transducers," Journal of Leukocyte Biology, vol. 74, no. 4, pp. 479-485, 2003.

[24] M. Levi, T. van der Poll, and H. R. Büller, "Bidirectional relation between inflammation and coagulation," Circulation, vol. 109, no. 22, pp. 2698-2704, 2004. 


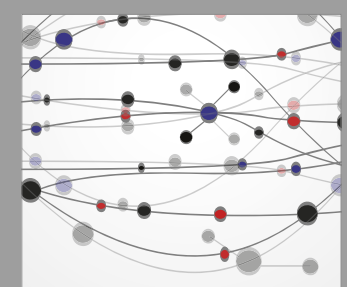

The Scientific World Journal
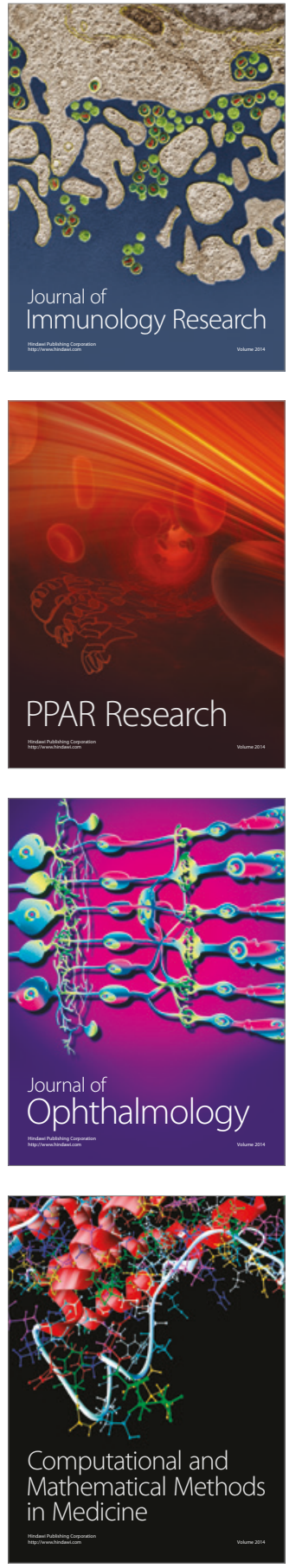

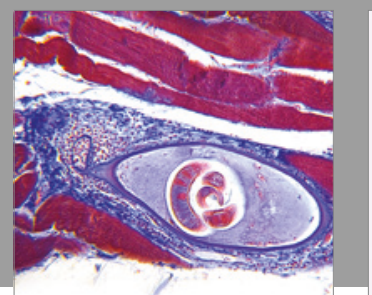

Gastroenterology Research and Practice
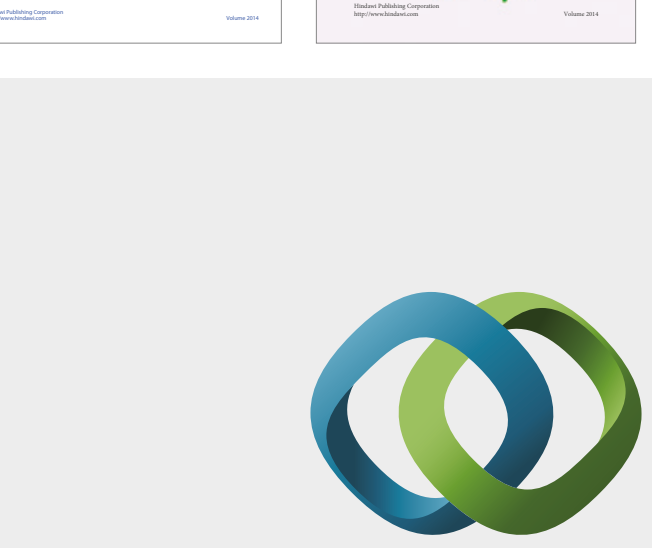

\section{Hindawi}

Submit your manuscripts at

https://www.hindawi.com
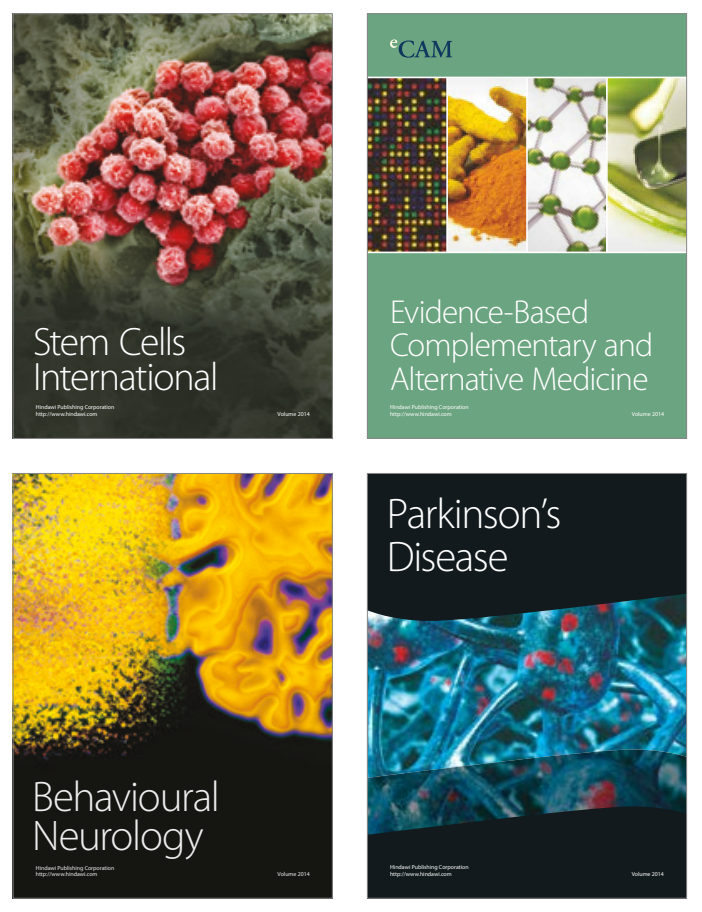
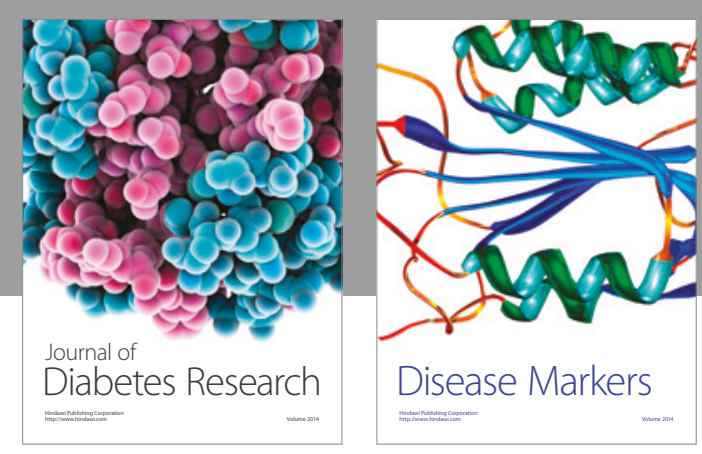

Disease Markers
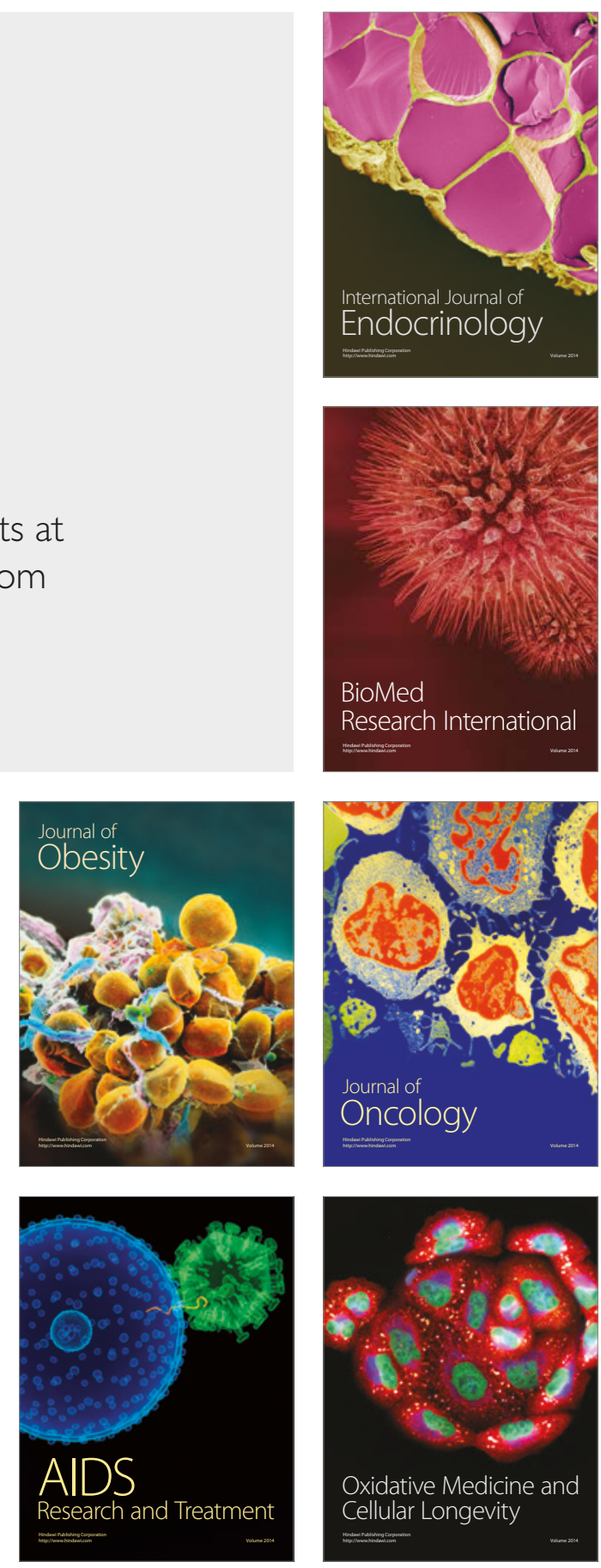